\title{
ANDRZEJ MĄDRO, MUZYKA A NOWE MEDIA. POLSKA TWÓRCZOŚĆ ELEKTROAKUSTYCZNA PRZEŁOMU XX I XXI WIEKU
}

Kraków 2017 Akademia Muzyczna w Krakowie, ss. 4I2, ISBN 978-83-62743-8I-O

Nowe media, tak bogato reprezentowane na festiwalach muzyki współczesnej, w refleksji muzykologicznej długo nie stanowiły zagadnienia w zadowalający sposób opracowanego. Choć twórczość polskich kompozytorów posługujących się na co dzień mediami elektronicznymi bywa omawiana oraz analizowana, to monografia Andrzeja Mądro stanowi ważną próbę syntetycznego i możliwie jak najszerszego spojrzenia na tę działalność. Książka, będąca pracą doktorską autora, napisaną pod kierunkiem prof. dr hab. Krystyny Wilkoszewskiej i obronioną w Akademii Muzycznej w Krakowie w 2015 r., stanowi istotna nowość na rynku wydawniczym z co najmniej dwóch powodów. Po pierwsze, jest jedną z niewielu monografii poświęconych 
polskiej muzyce elektroakustycznej. Warto podkreślić, że temat ten przez lata był zaniedbywany, a po Muzyce elektronicznej Włodzimierza Kotońskiego (pierwsze wydanie pochodzi z 1989 r.), nie podjęto próby szerszego opisania tego bogatego i bardzo szybko rozwijającego się nurtu w muzyce. Drugim powodem jest sposób ujęcia tematu przez Mądro. Autor stara się spojrzeć na muzykę elektroakustyczną z perspektywy medium, a więc narzędzi, jakimi artyści się posługują. Tym samym inicjuje na polskim gruncie to, co sam nazywa nurtem „muzykologii medialnej" (s. 19).

We „Wstępie” (s. 9-15) autor podkreśla, że termin „nowe media” rozumie możliwie szeroko, jako „środki techniczne i związane $\mathrm{z}$ nimi procesy oraz specyficzne materiały opracowywane w działaniu twórczym nie bezpośrednio, a jedynie za pomocą owych mediatyzujących środków technicznych" (definicja podana za Ryszardem Kluszczyńskim, s. 9). Mądro dodaje, że za muzykę nowych mediów uznaje wszelką twórczość elektroakustyczną. Szkoda jednak, że w tym miejscu nie podejmuje próby głębszej refleksji nad sposobem funkcjonowania pojęcia "nowe media” w dyskursie naukowym. Być może takie podsumowanie pozwoliłoby uniknąć niekonsekwencji terminologicznych, o których będzie jeszcze mowa w dalszej części recenzji. Należy w tym miejscu podkreślić, że wielokrotnie w pracy przywoływany Ryszard Kluszczyński jest teoretykiem zajmującym się multimediami, niemniej jego działalność skupia się przede wszystkim na sztukach wizualnych oraz audiowizualnych, związanych w pierwszej kolejności z filmem i sztuką video. Daje to do zrozumienia w pierwszym rozdziale książki dotyczącej interaktywności w sztuce oznajmiając, że „podejmowane tu rozważania będą zasadniczo i bezpośrednio dotyczyć [...] jedynie sztuk wizualnych i audiowizualnych, nie obejmują więc, a przynajmniej nie wprost i nie w sposób pretendujący do względnej choćby kompletności, sztuk me-

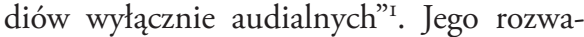
żania mogą zatem stanowić punkt wyjścia dla badacza muzyki, natomiast wymagają pewnych transformacji i uzupełnień. Mądro nie próbuje jednak stworzyć narzędzia metodologicznego, które mogłoby być w sposób uniwersalny wykorzystywane do badania muzyki elektroakustycznej. Skupia się raczej na wykorzystaniu istniejących już teorii i pojęć, syntetycznym ich przedstawieniu oraz próbie połączenia ich elementów w taki sposób, by wykreować spójny obraz muzyki współczesnej w kontekście przemian cywilizacyjnych i kulturowych. Mądro sam stwierdza, że „celem pracy jest także wyjaśnienie podstawowych dla tematyki pojęć i zaadaptowanie ich do dyskursu muzykologicznego" (s. Io). Cel ten zostaje o tyle osiągnięty, że autorowi udaje się wpisać działalność muzyczną w szerszy zakres historii sztuki i mediów. Jest to działanie potrzebne, szczególnie w sytuacji, gdy w muzycznej rzeczywistości akademickiej zagadnienia te funkcjonują $\mathrm{w}$ ograniczonym zakresie. Natomiast Akademie Sztuk Pięknych od lat zachęcają do studiów na wydziałach intermediów lub takich, które wpisują w swój program działania multimedialne i interaktywne. Nie dziwi więc fakt podkreślony przez Mądro (s. II), iż stan badań nad dziedziną muzyki nowych mediów pozostaje w tyle wobec pokrewnych dyscyplin - sztuk wizualnych i performatywnych oraz filmu. Próba zmiany tego stanu rzeczy jest tym bardziej godna pochwały.

Praca została podzielona na trzy zasadnicze części poprzedzone wstępem (s. 9-I5), a zwieńczone krótkimi uwagami końcowymi (s. 373-376). Całość uzupełnia rozbudowana bibliografia, z której wydzielone zostały teksty źródłowe dotyczące pięciorga kompozytorów (Stanisława Krupowicza, Magdaleny Długosz, Cezarego Duchnow-

I Ryszard Kluszczyński, Sztuka interaktywna. Od dzieta-instrumentu do interaktywnego spektaklu, Warszawa 20Io, s. I4. 
skiego, Krzysztofa Knittla, Marka Chołoniewskiego), źródłowy spis ilustracji oraz indeks nazwisk.

Pierwsza część, zatytułowana „Wprowadzenie - od trójjedynej chorei po sound art”, zarysowuje pięć zagadnień o naturze historycznej, które stanowiły podwaliny dla ukształtowania się sztuki nowych mediów. W pierwszej kolejności autor przybliża pojęcie medium, opisując kluczowe zmiany w zakresie podstawowego nośnika informacji i konsekwencje tych zmian dla kultury. Podkreślona została rola druku, natomiast nieco przemilczano temat samego zapisu muzycznego jako medium o znaczącym wszak wpływie na kształtowanie i rozwój muzyki zachodniej. Szczególnie, że Walter Ong, piewca podziału historii kultury na epokę oralną i piśmienną, pojawia się wśród cytowanych autorów, podobnie zresztą jak jego słynny nauczyciel Marshall McLuhan. Być może ze względu na potraktowanie medium z perspektywy technologicznej, co jest zrozumiałe w obliczu głównego tematu pracy, większą uwagę autora przyciągnął druk, który wpłynął nie tylko na ujednolicenie notacji oraz postępu w muzyce, ale również na jej umasowienie w XIX w. (s. 23). Następny podjęty temat to pojawienie się wynalazków i technologii o naturze audiowizualnej - od fotografii, przez początki filmu i telewizji, po przekaz satelitarny i wirtualną rzeczywistość. Krótko omówione zostały także początki i rozwój fonografii. Szkoda, że w tym miejscu autor nie przypomniał dziś już nieco nieaktualnej, ale mającej niezbywalną wartość historyczną książki Mieczysława Kominka², świadczącej o sposobie recepcji zagadnień związanych z szeroko rozumianymi nowymi mediami w Polsce lat osiemdziesiątych. Przypomnienie okoliczności rozpowszechnienia się telefonu i radia oraz mediów cyfrowych - komputera i Internetu rozszerza opisywane zagadnienia o perspek-

2 Mieczysław Kominek, Wszystko zaczęto się od fonografu, Kraków 1986. tywę komunikacyjną. Mądro cytuje w tym miejscu Lva Manovicha, u którego „nowe media” oznaczają media cyfrowe i jako takie stoją w opozycji do „mediów starych”, czyli analogowych. Mądro zamieszcza zresztą tabelę, która to rozróżnienie Manovicha skutecznie wyjaśnia (s. 38). Właściwe zrozumienie tego fragmentu wymaga od czytelnika uważności - wszak w całokształcie pracy Mądro rozumie „nowe media” dużo szerzej.

Drugi rozdział pierwszej części, „Elektrofony - nowe media dźwięku” (s. 43-74), to prezentacja historii rozwoju instrumentarium muzycznego - od instrumentów mechanicznych przez automatofony, aż po różnorodne instrumenty elektroniczne i elektroakustyczne. Anektowanie nowych technologii dla celów muzycznych obrazuje to, jak wiele etapów stało na drodze do powstania nowoczesnych syntezatorów oraz środowiska programowego. Autor przedstawia zagadnienie w sposób interesujący, przypominając nie tylko nazwiska doskonale znane, ale także takie, o których w Polsce rzadko się wspomina, jak choćby meksykańskiego teoretyka Carlosa Cháveza (s. 65) czy egipskiego kompozytora Halima El-Dabha (s. 77). Wyjście poza zachodnią perspektywę uświadamia czytelnikowi bogactwo i uniwersalność kreatywnej myśl muzycznej w pierwszej połowie XX wieku.

W kolejnych trzech rozdziałach autor kategoryzuje dźwiękową twórczość elektroakustyczną, wydzielając jej trzy nurty: czysto-muzyczny (rozdział I.3, s. 75-IO3), pogranicza performansu (rozdział I.4, s. IO3-II9), sztukę instalacji (rozdział I.5, s. I20-I39). Przyjęcie takiej perspektywy porządkuje bogaty materiał i chociaż poszczególne nurty często się przenikają, to cel systematyzacji zostaje osiągnięty. Choć nie explicite, to za pomocą tego trójpodziału Andrzej Mądro nawiązuje do kolejnych etapów dwudziestowiecznych zmian na gruncie relacji między poszczególnymi podmiotami zaangażowanymi w sytuację muzyczną. Pierwszy model mieści w sobie 
awangardowe i eksperymentalne działania, jednak pod względem pełnionych przez kompozytora, wykonawców i odbiorców ról może być postrzegany jako kontynuacja przez wieki budowanej tradycji. Kompozytor kreuje muzyczne światy, tyle że przy użyciu nowych narzędzi i dźwięków. Tym, co wzbudza pewne wątpliwości, jest wydzielenie, obok muzyki konkretnej i elektronicznej, musique acousmatique (s. 93). Nie jest dla mnie do końca jasny cel wydzielenia tej kategorii, która jest ściśle związana z muzyką konkretną, a jej istotą wydaje się być szczególny sposób słuchania, a nie komponowania. „Multimedialne spektakle - muzyka elektroakustyczna w sztuce performansu" to omówienie stopniowego wprowadzania elementów performansu do działań muzycznych w postaci happeningu, teatru instrumentalnego, a następnie zmediatyzowanych performansów i interaktywnych spektakli. W tej części omówione są zatem działania angażujące z jednej strony ciało twórcy, zaburzając tradycyjny rozdział ról kompozytora i wykonawcy, a z drugiej - ciało odbiorcy, zaprzeczając tradycji biernego odbioru. Ostatni rozdział w tej części „Od video-art po soundscape - muzyka elektroakustyczna w sztuce instalacyjnej” jest natomiast poświęcony działaniom, które nie tylko burzą kształt tradycyjnego odbioru wymagając całościowego zaangażowanie widza/słuchacza $\mathrm{w}$ działanie, ale także poddają w wątpliwość naturalny czasowy charakter sztuki muzycznej, zbliżając ją do sposobu funkcjonowania sztuk wizualnych i przestrzennych.

Podsumowując, w pierwszej części pracy Andrzejowi Mądro udało się syntetycznie zebrać imponująco szerokie spektrum zagadnień. Mimo ogromnego zakresu tematycznego, wywód jest prowadzony w sposób uporządkowany i elokwentny. Omówienia mają co prawda niekiedy może zbyt lapidarną formę, niemniej należy podkreślić, że autor konsekwentnie stara się wpleść polski wątek w ogólnoświatowy nurt rozwoju mu- zyki elektroakustycznej, a podjęte zagadnienia stanowią doskonały punkt wyjścia dla dalszych prac w tej dziedzinie.

Część druga, zatytułowana „Poetyka i estetyka twórczości elektroakustycznej” ma na celu umiejscowienie „problematyki badań w kontekście najważniejszych zagadnień technologicznych i estetycznych" (s. I2). Wobec tak wyznaczonego tematu, Mądro poddaje refleksji w pierwszej kolejności kluczowe pojęcia związane ze sztuką nowomedialną: multimedia, intermedia i hipermedia, a następnie interaktywność i wirtualność. Rozróżnienie trzech pierwszych nie jest zadaniem trywialnym, w literaturze bowiem częstokroć są używane niemal wymiennie. Mądro przywołuje konteksty posługiwania się każdym z nich, próbując ukazać ich zniuansowanie. Ostatecznie, zdaje się przyjmować za Nicholasem Cookiem postawę, w której multimedia stanowią kategorię najbardziej ogólną, w której mieszczą się zarówno intermedia, jak i hipermedia. W sposób dokładniejszy Mądro podejmuje temat interaktywności. Jako interaktywne określa on takie utwory, w których „odbiorca może wpływać na kształt finalny dzieła sztuki - poprzez media elektroniczne [...]" (s. I48). W tym fragmencie już wprost porusza zagadnienie budowania relacji twórca-dzieło na etapie koncepcji oraz dzieło-odbiorca na etapie „wykonania” oraz przewartościowanie tych relacji w obliczu wykorzystania nowych mediów. Zaskakuje jednak konstatacja, iż „potencjał muzycznych interakcji pojawił się, gdy tylko postęp techniki umożliwił wytwarzanie i przetwarzanie dźwięków za pomocą rozmaitych urządzeń cyfrowych" (s. I5I). Wydaje się bowiem, że potencjał ten ujawnił się dużo wcześniej - choćby w twórczości bazującej na metodach stochastycznych, aleatorycznych oraz $\mathrm{w}$ muzycznych akcjach angażujących publiczność. W zakresie relacji dzieło-odbiorca interakcja może zresztą zachodzić bez względu na stopień technologicznego zaawansowania 
medium elektroakustycznego. Przykładem mogą być choćby wariabilne pod względem formalnym utwory Kazimierza Serockiego oraz kompozycje przestrzenno-muzyczne Zygmunta Krauzego, które, mimo analogowej technologii, zmuszały uczestnika do aktywnej percepcji (czy też, jak można rzec, korzystając z nomenklatury Antoniego Porczaka - „percepcji operacyjnej”). Natomiast rozważane w następnej kolejności pojęcie wirtualności jest już słusznie łączone z przekazami w przestrzeni cyfrowej.

Drugi rozdział środkowej części autor poświęca zagadnieniu dźwięku i brzmienia („Elektroakustyka i nowa brzmieniowość od sztuki hałasów po barwy syntetyczne", s. I6I-I87). Wyjaśnia pojęcia i łączy perspektywę psychoakustyczną i kognitywną. Wymienia między innymi szereg określeń mających służyć do opisu barwy, które jednak, jak sam stwierdza, nie przyjęły się na gruncie analizy muzykologicznej. Nie znajdują również zastosowania w części poświęconej twórczości kompozytorskiej. Opisanie efektów brzmieniowych możliwych do osiągnięcia przy wykorzystaniu technologii analogowej oraz cyfrowej z pewnością dają jednak ogląd zmian, jakie zaszły na gruncie kreowania muzyki, a także bogactwa narzędzi, jakimi dysponują współcześni twórcy. Po dość szczegółowym omówieniu metod syntezy dźwięku i możliwych do osiągnięcia efektów dźwiękowych, autor opisuje rolę barwy w twórczości kompozytorskiej XX i XXI w. oraz emancypację szumu. Szkoda, że charakterystyczna dla twórczości polskich kompozytorów lat sześćdziesiątych sonorystyka została zaledwie wspomniana, szczególnie że jest to temat szeroko przez polskich uczonych przebadany. Być może nieco dokładniejsze zgłębienie tego zagadnienia mogłoby dać asumpt do wysnucia dodatkowych wniosków dotyczących polskiej twórczości elektroakustycznej.

Bardzo dobrze Mądro poradził sobie $\mathrm{z}$ omówieniem niełatwego zagadnienia przestrzeni i przestrzenności (rozdział 2.3, s. I87-2I2). Temat podjęty został zarówno z punktu widzenia fizycznego rozstawiania wykonawców w przestrzeni sali koncertowej, jak i w dalszej kolejności - z punktu widzenia wykorzystania nowych mediów w celu osiągnięcia konkretnych przestrzennych wrażeń u odbiorcy. Co więcej, autor zauważa i podkreśla wieloznaczność pojęcia w dyskursie muzykologicznym. Mimo przyjęcia szerokiego kontekstu, potrafi zachować proporcję i ciągłość narracji, której tematyka pozostaje wciąż w kręgu muzyki elektroakustycznej Od zagadnień przestrzenności, gładko przechodzi do zagadnień z tym tematem w sposób szczególny związanych, poświęcając kolejny rozdział percepcji i zmianom, jakie na tym gruncie zaszły w związku z pojawienia się nowych technologii (rozdział 2.4, s. 212-224). To kolejny ogromny temat, który został przedstawiony w sposób syntetyczny, ale wystarczający, z odwołaniem się zarówno do perspektywy psychologicznej, jak i komunikacyjnej. Doskonałym uzupełnieniem tego fragmentu byłoby przedstawienie choćby elementów fizjologii ludzkiego słyszenia, z którego przecież wynika bezpośrednio sposób kształtowania poszczególnych elementów muzyki. Przywołana w tym miejscu teoria sceny słuchowej Alberta Bregmana, choć wpisująca się w kontekst rozdziału, nie znajduje zastosowania w części ostatniej - poświęconej twórczości wybranych kompozytorów. Mądro kończy rozdział ciekawym podsumowaniem, w którym stwierdza wzajemne i nieustanne wpływanie na siebie mediów, sztuki i percepcji (s. 233).

Część trzecia jest w całości poświęcona twórczości polskich kompozytorów. Mądro wybrał pięcioro twórców, których działalność w dziedzinie muzyki elektroakustycznej uznał z jednej strony za szczególnie wyróżniającą się, a z drugiej na tyle różnorodną, by jej omówienie mogło stanowić reprezentację środowiska oraz egzemplifikację zjawisk i nurtów omówionych w dwóch pierwszych częściach pracy. Poddana reflek- 
sji zostaje zatem twórczość Stanisława Krupowicza (ur. 1952), Magdaleny Długosz (ur. I954), Cezarego Duchnowskiego (ur. I97I), Krzysztofa Knittla (ur. 1947) oraz Marka Chołoniewskiego (ur. 1953). Nie ulega wątpliwości, że twórcy ci to wybitne osobowości, odgrywające istotną rolę w dziedzinie polskiej muzyki elektroakustycznej - zarówno w zakresie kompozycji, jak i organizacji imprez na rzecz popularyzacji i rozwoju muzyki skupionej wokół nowych mediów. Oczywiste jest, że przez omówienie twórczości pięciorga kompozytorów trudno scharakteryzować działalność całego środowiska skupionego wokół muzyki elektroakustycznej, która w Polsce ma bogatą historię, wyrastającą choćby z działalności Studia Eksperymentalnego Polskiego Radia (poza Krupowiczem, wszyscy wybrani twórcy mają na swoim koncie nagrania niezrealizowane w tej instytucji). Dobrze, że autor zadbał, by wśród omówionych twórców znalazła się choć jedna kobieta, a także jeden przedstawiciel młodszego pokolenia kompozytorów (Duchnowski).

Układ rozdziałów w ramach tej części, a zatem kolejność omawianych kompozytorów, nawiązuje do systematyki działalności elektroakustycznej scharakteryzowanej w pierwszej części pracy. W pierwszej kolejności Mądro omawia twórczość Stanisława Krupowicza, kompozytora wykorzystującego media elektroniczne nie tylko podczas prezentacji utworu, ale już na etapie jego tworzenia. Jego „kwintet dęty ARDO 403I z 1979 to pierwsza w Polsce kompozycja, której materiał dźwiękowy wygenerowany został przez komputer” (s. 239). By lepiej zrozumieć algorytmiczne metody twórcze tego kompozytora, wystarczy wrócić do rozdziału dotyczącego metod syntezy dźwięku (rozdział 2.2.3).

W następnej kolejności Mądro omawia twórczość Magdaleny Długosz. W przeciwieństwie do Krupowicza poszukującego w nowych mediach narzędzia matematycznego kreowania kompozycji, krakowska kompozytorka media elektroniczne traktuje jako źródło nieograniczonych możliwości w kształtowaniu barwy, przestrzeni i muzycznej ekspresji. Mądro wpisuje ją w nurt muzyki akuzmatycznej, choć równie dobrze należałoby szukać źródeł takiego traktowania materii dźwiękowej w polskiej szkole sonorystycznej. Dla kompozytorki media są przedłużeniem akustycznych instrumentów, których brzmienie uważa za najdoskonalsze. Stąd też jej zainteresowanie z jednej strony muzyką konkretną, a z drugiej strony tym, co Mądro nazywa nurtem person-specific (s. 268). Długosz tworzy utwory dla konkretnych wykonawców, a media elektroniczne pozwalają jej uwypuklić subtelności gry wybranych przez nią artystów. Takie wykorzystanie medium pozwala jej zanurzyć uczestnika w koncertowym wydarzeniu (immersja) przy jednoczesnym zatarciu granic między brzmieniem naturalnym, przetworzonym oraz sztucznym. Mimo ścisłej współpracy z wykonawcami, kompozytorka nie pozostawia miejsca na swobodną improwizację, zachowując całkowitą odpowiedzialność za końcowy rezultat.

Natomiast twórca festiwalu Musica Electronica Nova, Cezary Duchnowski, najmłodszy $\mathrm{z}$ omawianych twórców, prezentuje postawę otwartą. Jego muzyka często jest kreowana na żywo podczas koncertowego wykonania. W przeciwieństwie do Długosz, znajduje w swej twórczości szerokie zastosowanie dla live electronics. Interesuje go niejednorodność narracji, poszarpana forma i improwizacja, która pozwala na żywo kreować warstwę audialną utworu, a jednocześnie poszukiwać coraz to nowych rozwiązań i środków wypowiedzi.

Dzieła dwóch pozostałych kompozytorów - Krzysztofa Knittla i Marka Chołoniewskiego - mają obrazować multimedialne eksperymenty na pograniczu performansu i instalacji (por. rozdziały I.4. oraz I.5). Obydwaj twórcy w centrum zainteresowań stawiają projekty multimedialne, w których istotną rolę pełni improwizacja. Każdy 
z nich realizuje te cele w inny sposób. Knittel korzysta z nagrań, ale także eksperymentuje z nowymi instrumentami. Natomiast Chołoniewski od początku kariery tworzy systemy komputerowe, które stanowią narzędzia interakcji w jego utworach, performansach i instalacjach. Warstwa wizualna jest ściśle powiązana $\mathrm{z}$ audialną, a sposób działania wykonawców i publiczności ma realny wpływ na ostateczne brzmienie danego wykonania. Twórca staje się zaledwie inicjatorem działania, którego audiowizualny efekt zależy od szeregu splotów okoliczności i działań.

Niewątpliwą zasługą autora recenzowanej książki jest scharakteryzowanie i omówienie twórczości kompozytorów, o których nie powstały jeszcze żadne dogłębne opracowania. Nie ulega wątpliwości, że szeroki zakres działalności każdego z nich zasługuje na dokładniejszą analizę, na którą w tej przekrojowej pracy nie mogło być już miejsca. Część poświęcona wybranym twórcom muzyki elektroakustycznej jest zwieńczona krótkim podsumowaniem (rozdział 3.6, s. 367-37I), w którym autor wymienia poszczególne zjawiska sztuki dźwiękowej, wspominając kompozytorów, w których dorobku artystycznym można je odnaleźć. Wykazana w ten sposób różnorodność zakresu wykorzystania nowych mediów w muzyce jest imponująca. $Z$ całą pewnością teoria zaprezentowana w I i II części pracy znajduje odzwierciedlenie $\mathrm{w}$ praktyce kompozytorskiej wybranych twórców (część III), choć niektóre związki uwypuklone zostały dopiero w tym nieco nazbyt lapidarnym podsumowaniu. Natomiast szeroka perspektywa teoretyczna zakreślona przez autora, powinna stanowić zachętę dla prowadzenia dalszych szczegółowych badań zarówno w zakresie relacji media-muzyka, jak i w zakresie analiz twórczości kompozytorskiej. Cennym dopełnieniem pracy byłoby porównanie działalności wybranych artystów oraz wyodrębnienie wspólnych dla ich twórczości cech. Wydaje się bowiem, że w przypadku muzyki elektroakustycznej, a w szczególności multimedialnej i interaktywnej, istotna jest nie tylko samodzielna praca kompozytora, lecz także ścisła współpraca $\mathrm{z}$ wykonawcami specjalizującymi się $\mathrm{w}$ tego typu realizacjach oraz $\mathrm{z}$ instytucjami zainteresowanymi prezentowaniem tej twórczości.

$\mathrm{Na}$ koniec warto zwrócić uwagę na przejrzystą strukturę recenzowanej książki. Każdy rozdział jest poprzedzony wstępem sygnalizującym zagadnienia, które będą w nim omawiane. Tekst jest podzielony na krótkie podrozdziały - każdy o własnym tytule. Ułatwia to znacznie podążanie za tokiem myślenia autora. Jednocześnie rozbudowany spis treści umożliwia łatwy powrót do potrzebnych w danej chwili fragmentów, co w pewnym stopniu zastępuje nieobecny w pracy indeks tematyczny. Taki rozczłonkowany układ pracy stanowi również zaletę z punktu widzenia działalności dydaktycznej. Szerokie spektrum omawianych zagadnień, a także przystępny język oraz poprawna stylistyka sprawiają, że monografia może z powodzeniem pełnić funkcję lektury wykorzystywanej na zajęciach $\mathrm{z}$ historii muzyki XX w., czy wstępu do współczesnej kompozycji. Należy docenić problemowy układ omawianych zagadnień, nawet jeśli niekiedy odbywa się to kosztem scharakteryzowania niektórych istotnych dla rozwoju twórczości elektroakustycznej nurtów. Jednakże struktura pracy, a także jej budowa każą sądzić, że opracowana w ostatniej części twórczość elektroakustyczna polskich kompozytorów stanowi jedynie egzemplifikację dla zjawisk omówionych w pierwszej i drugiej części pracy, co powoduje wrażenie pewnej nieadekwatności tytułu książki sugerującego badania w głównej mierze nad twórczością elektroakustyczną, a nie nad jej kontekstami. Ze względu jednak na pionierski charakter podjętej pracy oraz otwarcie szeregu drzwi prowadzących do dalszych badań muzyki elektroakustycznej, należy monografię uznać za bardzo udaną 
i na wskroś odpowiadającą na potrzeby wydawniczego rynku muzycznego. Ważne, by multimedia przestały być tylko domeną festiwali, koncertów, czy wybiórczych opracowań, ale stały się również przedmiotem poważnych naukowych interdyscyplinarnych rozpraw. Jedynie przekroczenie podziału na tradycyjne dyscypliny pozwoli na gruntowne badanie twórczości, w której dźwięk, obraz, akcja, a także technologia i estetyka odgrywają równoważną rolę. Monografia Andrzeja Mądro doskonale wskazuje, jak wiele ścieżek jest jeszcze nieprzetartych i w jak wielu kierunkach takie badania mogą zmierzać.

Marta Dziewanowska-Pachowska Uniwersytet Muzyczny Fryderyka Chopina

\title{
Nowa seria wydawnicza Instytutu Sztuki PAN „Muzyka polska za granica”
}

\author{
Tom 1: Twórcy-źródła - archiwa
}

red. Beata Bolestawska-Lewandowska i Jolanta Guay-Pasiak

iswydawnictwo@ispan.pl

\section{Nowy tom „Monumenta Musicae in Polonia”}

\section{Władysław Żeleński. Goplana}

wydanie faksymilowe / facsimile edition

wydat $i$ wstepem opatrayt / edited and introduced by Grzegorz Zieziula

\author{
www.ispan.pl \\ iswydawnictwo@ispan.pl
}

